\title{
Atuação do trabalho em redes: estudo de caso com uma puérpera
}

\section{Performance of work in networks: a case study with a postpartum}

Débora Cristina Haack Bassani ${ }^{1}$, Jéssica Chaves $^{1}$, Camila Braga Derlan ${ }^{2}$, Manuela Filter Allgayer ${ }^{3}$, Bianca Ghignatti ${ }^{4}$, Janine Koepp ${ }^{5}$, Lia Possuelo ${ }^{6}$

1. Acadêmica do curso de Medicina da Universidade de Santa Cruz do Sul (UNISC), Santa Cruz do Sul, RS, Brasil. 2. Acadêmica do curso de Farmácia da Universidade de Santa Cruz do Sul (UNISC), Santa Cruz do Sul, RS, Brasil. 3. Acadêmica do curso de Enfermagem da Universidade de Santa Cruz do Sul (UNISC), Santa Cruz do Sul, RS, Brasil. 4. Enfermeira na maternidade do Hospital Santa Cruz, Santa Cruz do Sul, RS, Brasil e preceptora do Pro-Pet-Saúde Redes de Atenção Subprojeto Rede Cegonha. 5. Professora do curso de enfermagem da Universidade de Santa Cruz do Sul, Santa Cruz do Sul, RS, Brasil e tutora do Pro-Pet-Saúde Redes de Atenção Subprojeto Rede Cegonha. 6. Professora do Departamento de Biologia e Farmácia da Universidade de Santa Cruz do Sul, Santa Cruz do Sul, RS, Brasil e Coordenadora do Pro-Pet-Saúde Redes de Atenção

\section{Resumo}

O estudo objetivou avaliar a importância do trabalho em redes e a ação multidisciplinar dos diferentes níveis de atenção em saúde. Estudo descritivo, de abordagem qualitativa, do tipo estudo de caso. Foi realizada uma entrevista com uma puérpera, e feita uma consulta ao prontuário da paciente. A pesquisa foi realizada em um hospital do interior do estado do Rio Grande do Sul. S.A.T., 28 anos, 35 semanas de idade gestacional, chega ao Pronto Atendimento em trabalho de parto após uso de Misoprostol. Houve o acompanhamento do caso no Centro de Referência da Assistência Social e Estratégia de Saúde da Família.

Palavras-chave: Humanização. Misoprostol. Assistência social. Apoio social.

\begin{abstract}
The study aimed at evaluating the importance of working in networks and multidisciplinary action at different levels of health care. Descriptive study, qualitative approach, case study type. An interview with a postpartum was performed, and an appointment was made to record the patient. The survey was conducted at a hospital in the state of RS. SAT, 28, 35 weeks of gestational age, the woman arrived at the Emergency Service into labor after taking Misoprostol. There was monitoring of the case in the Reference Center for Social Assistance and Family Health Strategy.
\end{abstract}

Keywords: Humanization. Misoprostol. Social assistance. Social support.

\section{INTRODUÇÃO}

A Política Nacional de Assistência Social, na perspectiva do Sistema Único de Assistência Social, ressalta o campo da informação, o monitoramento e a avaliação, podendo e devendo ser considerados como meios estratégicos para uma melhor atuação no tocante às políticas sociais e a uma nova concepção no campo da política de assistência social. A proteção social exige a capacidade de maior aproximação possível do cotidiano da vida das pessoas, pois é nele que os riscos e as vulnerabilidades se constituem ${ }^{1}$.

A proteção social deve garantir as seguintes seguranças: segurança de sobrevivência (de rendimento e de autonomia); de acolhida e de convívio ou vivência familiar. Por segurança da acolhida entende-se como uma das seguranças primordiais da política de assistência social. Ela opera com a provisão de necessidades humanas que se inicia com os direitos à alimentação, ao vestuário e ao abrigo, que são próprios à vida humana em sociedade. A conquista da autonomia na provisão dessas necessidades básicas é a orientação desta segurança da assistência social. Outra situação que pode demandar acolhida, nos tempos atuais, é a necessidade de separação da família ou da parentela por múltiplas situações, como violência familiar ou social, drogadição, alcoolismo, desemprego prolongado e criminalidade. Constitui o público usuário da Política de Assistência Social cidadãos e grupos que se encontram em situações de vulnerabilidade e riscos ${ }^{1}$.

O Centro de Referência da Assistência Social - CRAS é uma unidade pública estatal de base territorial, localizado em áreas de vulnerabilidade social. Executa serviços de proteção social básica, organiza e coordena a rede de serviços socioassistenciais locais da política de assistência social. O CRAS atua com famílias e indivíduos em seu contexto comunitário, visando à orientação e ao convívio sociofamiliar e comunitário. Nesse sentido, é responsável pela oferta do Programa de Atenção Integral às Famílias. Já o Estatuto da Criança e do Adolescente (ECA), no Art. 4으, refere que é dever da família, da comunidade, da sociedade em geral e do poder público assegurar, com

Correspondência: Jéssica Chaves. Universidade de Santa Cruz do Sul (UNISC). Campus Universitário. CEP: 96.815-900 - Santa Cruz do Sul, RS, Brasil. Telefone: (51) 37177300. E-mail: jessykasacht@yahoo.com.br

Conflito de interesse: Não há conflito de interesse por parte de qualquer um dos autores.

Recebido em: 16 Out 2014; Revisado em: 18 Nov 2014; Aceito em: 30 Nov 2014. 
absoluta prioridade, a efetivação dos direitos referentes à vida, à saúde, à alimentação, à educação, ao esporte, ao lazer, à profissionalização, à cultura, à dignidade, ao respeito, à liberdade e à convivência familiar e comunitária. Em seu parágrafo único, a garantia de prioridade compreende: a) primazia de receber proteção e socorro em quaisquer circunstâncias; b) precedência de atendimento nos serviços públicos ou de relevância pública; c) preferência na formulação e na execução das políticas sociais públicas; d) destinação privilegiada de recursos públicos nas áreas relacionadas com a proteção à infância e à juventude ${ }^{5}$.

Tanto o trabalho em redes, como a política de assistência social abrangem na sua atuação o processo de humanização, que consiste em uma esfera que atravessa todas as instâncias do SUS e se propõe a atuar na descentralização, isto é, na autonomia administrativa da gestão da rede de serviços, de maneira a articular os processos de trabalho e as relações entre os diferentes profissionais e a população atendida. Para tanto, cabe às equipes prepararem-se para lidar com a dimensão subjetiva nas práticas do cotidiano profissional ${ }^{2}$.

No que se refere ao uso do Misoprostol para interrupção ilegal da gravidez, visualiza-se o trabalho em redes, que tem importância na participação ao tentar humanizar as ações do cuidado em família. O Misoprostol é um análogo sintético de prostaglandina E1 efetivo no tratamento e na prevenção de úlcera gástrica induzida por anti-inflamatórios não hormonais. Ele tem utilidade na obstetrícia, pois dispõe de ação úterotônica e de amolecimento do colo uterino, na indução de aborto legal, no esvaziamento uterino por morte embrionária ou fetal, no amolecimento cervical antes de aborto cirúrgico (AMIU ou curetagem) e na indução de trabalho de parto (maturação de colo uterino). Esse produto foi comercializado sem restrições nas farmácias e nas drogarias até julho de 1991, quando o Ministério da Saúde proibiu a venda sem apresentação e retenção da prescrição médica. Atualmente, a Portaria no 344, publicada pelo Ministério da Saúde, em vigor desde 1998, restringe a compra e o uso do Misoprostol aos estabelecimentos hospitalares cadastrados junto à Agência Nacional de Vigilância Sanitária (Anvisa). Entretanto, os veículos de comunicação de massa têm denunciado a venda clandestina do produto em farmácias e drogarias, comércio ambulante e, até mesmo, pela internet. Em 2006, a Anvisa proibiu a venda desse produto via internet, mas essa iniciativa tem-se mostrado pouco efetiva para impedir o comércio via rede mundial de computadores ${ }^{3,4}$.

O objetivo desse estudo é avaliar a importância da atuação do trabalho em redes e a ação multidisciplinar entre os diferentes níveis de complexidade de atenção em saúde em um município do interior do estado do Rio Grande do Sul.

\section{RELATO DE CASO}

Trata-se de um estudo descritivo, com uma abordagem qualitativa, do tipo estudo de caso. Foi realizada uma entrevista informal com uma puérpera, no dia 29 de julho de 2013, a fim de elucidar as informações necessárias para a descrição do estudo.
Também foi feita uma consulta ao prontuário da paciente, com coleta da descrição do exame físico do recém-nascido. Além disso, foi colhido um relato da assistente social responsável pelo caso. A pesquisa das informações foi realizada na maternidade de um hospital do interior do estado do Rio Grande do Sul, no período de 29 de julho a 12 de agosto de 2013.

S. A. T. de A., 28 anos, 35 semanas de idade gestacional (IG) por capurro, chega ao Pronto Atendimento (PA) do HSC, em trabalho de parto após uso de Misoprostol (Citotec). A puérpera referiu que fazia uso de anticoncepcional via oral combinado, mas que apresentava muitos efeitos adversos, como fadiga e náuseas. Antes de comprovar a gravidez, relatou sentir mudanças corporais, como fadiga, mastalgia, dor nas costas e abdome mais saliente, mas sem ocorrer interrupção da menstruação. Ao sentir essas alterações, submeteu-se a dois testes de gravidez comprados na farmácia, com resultado positivo em ambos. A puérpera relatou a decisão de ter comprado em caráter ilegal o medicamento Misoprostol para a interrupção da gravidez não planejada. Foram administrados, por via oral, dois comprimidos do fármaco no sexto mês de gestação. Ao sentir contrações e sangramento, procurou o HSC.

No hospital, a gestante realizou parto vaginal, com recémnascido (RN) apresentando Apgar 8/9, peso de 2.165 gramas, comprimento de $44 \mathrm{~cm}$, perímetro cefálico de $30 \mathrm{~cm}$, perímetro torácico de $28 \mathrm{~cm}$, choro forte ao nascer, movimentos respiratórios regulares, ativos, com frequência cardíaca (FC) maior que $100 \mathrm{bpm}$ e acrocianose, mucosas úmidas e coradas, palato íntegro, fontanela normotensa, suturas alinhadas, clavículas sem sinais de instabilidade óssea e reflexos do RN presentes, sem ausculta de sopro. Ruídos Hidroaéreos (RHA) presentes, abdome plano e normotenso, sem visceromegalias. No coto umbilical, visualizam-se duas artérias e uma veia, pulsos simétricos, boa perfusão, períneo íntegro, genitália externa feminina, ortolani negativo bilateral, ânus e coanas pérveos. Interno na Unidade de Cuidados Intermediários (UCI), em ótimo estado geral. O líquido amniótico apresentou odor forte, e, por isso, foi solicitado hemograma completo. Os medicamentos prescritos foram Vitelinato de prata $10 \% \mathrm{FR} / 5 \mathrm{~mL}$ por via oftálmica, Fitomenadiona $10 \mathrm{mg} / 1 \mathrm{~mL}$ por via intramuscular e soro glicose $10 \% / 250 \mathrm{~mL}-7$ microgotas/min.

No relato da assistente social, a irmã de S. A. T. de A., ao tomar conhecimento da situação, procurou o pai da criança e lhe informou do ocorrido, e ele resolveu se responsabilizar pela criança. Quando isso aconteceu, S. A. T. de A. decidiu que não mais queria abortar, ou encaminhar seu bebê para doação, e desejou ficar com o RN. No hospital, ao ser solicitado o endereço, a mãe da criança não soube informá-lo. Devido à problemática relatada, o Serviço Integrado de Atendimento Psicossocial (SIAP) da Instituição foi acionado para auxiliar no caso. O Conselho Tutelar foi acionado e entrou em contato com o pai da criança, um senhor casado com outra mulher. $O$ pai informou ao Conselho que daria o devido apoio financeiro, mas com a condição de que a mãe ficasse com a criança. Conforme documento emitido pelo Conselho Tutelar, o RN poderá receber 
alta hospitalar acompanhada pelos pais ou responsáveis. Foram realizados os encaminhamentos necessários para o acompanhamento no Centro de Referência da Assistência Social (CRAS) e Estratégia de Saúde da Família (ESF). O pai do RN assinou um termo de responsabilidade que assegura os direitos previstos no Art. 40 do Estatuto da Criança e do Adolescente (ECA). O não cumprimento do termo acarretará a aplicação de medidas cabíveis em lei.

\section{DISCUSSÃO}

Dessa forma, destaca-se a importância do trabalho em redes, com ênfase na multidisciplinaridade, voltado para a humanização do cuidado. Percebe-se, como fator essencial, a atuação do CRAS, ECA e fiscalização da compra ilegal de medicamentos de uso comercial proibido, no caso o Misoprostol.

Embora ainda hoje se questione se os brasileiros têm acesso às ações e aos serviços de saúde com um adequado grau de resolutividade, se as ações e os serviços estão sendo planejados de acordo com as reais necessidades da população e com as condições de saúde do local e se os recursos estão sendo mobilizados de forma adequada visando a uma assistência de qualidade, houve, nesse estudo, uma real e rápida efetividade das ações em rede e da Política Nacional de Assistência Social.

\section{REFERENCIAS}

1. Ministério do Desenvolvimento Social e Combate à Fome (Brasil). Secretaria Nacional de Assistência Social. Política Nacional de Assistência Social PNAS/ 2004. Norma Operacional Básica NOB/SUAS. Brasília: SNAS; 2005.

2. Ministério da Saúde (Brasil). Secretaria de Atenção à Saúde. Política Nacional de Humanização da Atenção e Gestão do SUS. Trabalho e redes de saúde. Brasília: SAS; 2009.

3. Ministério da Saúde (Brasil). Secretaria de Atenção à Saúde. Núcleo Técnico da Política Nacional de Humanização. Trabalho e redes de saúde: valorização dos trabalhadores da saúde.2. ed. Brasília: Ministério da Saúde, 2008.

4. Brasil. Portaria n. 4.279, de 30 de dezembro de 2010. Estabelece diretrizes para a organização da Rede de Atenção à Saúde no âmbito do Sistema Único de Saúde (SUS). Diário Oficial [da] República Federativa do Brasil. 2010 dez. 30; Seção 1. [acesso em 2014 nov. 24]. Disponível em: http://bvsms.saude.gov.br/ bvs/saudelegis/gm/2010/prt4279_30_12_2010.html.

5. Brasil. Lei no 8.069, de 13 de julho de 1990. Dispõe do estatuto da Criança e do Adolescente e dá outras providências. Diário Oficial [da] República Federativa do Brasil. 1990 jul. 16; Seção 1. p.13563.
6. Brasil. Ministério da Saúde. Redes de Atenção à Saúde no Sistema Único de Saúde [Internet]. Brasília: Ministério da Saúde; 2012 [acesso em 10 de abril de 2014]. Disponível em: http://www.google.com.br/url?sa=t\&rct=j\&q=\&esr $c=s \&$ source=web\&cd=12\&sqi=2\&ved=0CF0QFjAL\&url=http\%3A\%2F\%2Fecosredenutri.bvs.br\%2Ftiki

7. Mengue SS, Pizzol TSD. Misoprostol, aborto e malformações congênitas. Rev Bras Ginecol Obstet. 2008; 30(6): 271-3.

8. Lavras $C$. Atenção primária à saúde e a organização de redes regionais de atenção à saúde no Brasil. Saúde e soc. 2011 out.- dez.; 20(4). doi: http://dx.doi. org/10.1590/S0104-12902011000400005

9. Mendes EV. As redes de atenção à saúde. Brasília: Organização Pan-Americana da Saúde, 2011.

10. Ministério da Saúde (Brasil). Secretaria de Atenção à Saúde. Departamento de Ações Programáticas Estratégicas. Protocolo Misoprostol. Brasília: SAS; 2012.

11. Pessoa LR, coordenador. Manual do gerente: desafios da média gerência na saúde. Rio de Janeiro: Ensp; 2011. 